\title{
Congenital heart surgery avidly awaits evidence
}

\section{Om Prakash Yadava ${ }^{1}$}

Published online: 15 January 2021

(C) Indian Association of Cardiovascular-Thoracic Surgeons 2021

Lack of Research, poor research, and poorly reported research are violations of children's human rights.

Richard Horton.

Plenary address to $1^{\text {st }}$ StaR Child Health Summit 2009.

Our last thematic issue was on Heart Transplant and my Editorial was titled 'Heart Transplant and Mechanical Circulatory Support - The Last Frontier?' [1]. In terms of engineering and mechanics, that may be an apt statement. However, when it comes to the art, grace and finesse, then probably nothing matches congenital heart surgery. No wonder then, a special issue on 'Surgery for Congenital Heart Diseases' was a natural follow-up issue.

Lately, surgeons have ceded simpler congenital cardiac lesions to our interventional cardiology colleagues and a congenital heart surgeon is confronted with complex scenarios and technically demanding surgeries, requiring astute decision-making. There is no scope for trial and error in paediatric cardiac surgery, and therefore, it becomes all the more important that one learns from the experiences of pioneers in the field and avoid repeating the same mistakes, in order to make the field safe for all our patients. This issue is littered with pearls, which the stalwarts have developed diligently over scores of years, and are there for grabs. The onus thus is on the reader and the budding surgeons to pick them up and incorporate them in their day-to-day practice.

Moreover, we have been bemoaning for long the lack of Indian data for most cardiac surgical procedures, more so congenital heart surgeries. This also becomes a major roadblock in generating guidelines. We therefore decided to have an entirely Indian authorship under the stewardship of Dr. Rajesh Sharma, a renowned Congenital Heart Surgeon, as

Om Prakash Yadava

op_yadava@yahoo.com

1 National Heart Institute, New Delhi, India the Guest Editor, with a view to attempt filling that void, at least to some extent. This issue is not a full compendium and certain missing titles shall be covered, either in a follow-up thematic issue or as reviews in regular issues. However, we do hope, this volume acts as a starting point, a kind of setting the ball rolling, in order to sensitize and encourage all the cardiovascular and thoracic surgeons of the country to document, collate, analyse and present their data, so that we can come out with authentic Indian statistics, not only for our own consumption but also for wider dissemination to rest of the world. Our data would also be extremely useful to all the countries in Southeast Asia, which share the same epidemiology and spectrum of heart diseases as us.

However, no matter the nobility of intent, there are barriers and hurdles to be surmounted. There is a high degree of heterogeneity in structural congenital cardiac ailments, and probably in no field of medicine are two patients as different for the same pathology as in congenital heart diseases. Carrying out randomized controlled trials (RCTs) in paediatric cardiac disorders is thus relatively difficult, and as a corollary, uncommon (Fig. 1). Most of the recommendations are based on expert opinion and data from studies with small number of cases (Fig. 2), with a level 'B' or ' $\mathrm{C}$ ' recommendation. Getting informed by data from these small observational studies is fraught with danger. Moreover, 'It is a founding principle of paediatrics that, 'children are not just small adults', yet many aspects of current practice have been extrapolated from adult studies, using 'hand-me-down' paradigms with little or no paediatric data to support their application' [2].

In fact, in a recent systematic review of RCTs in children's heart surgery in the twenty-first century, Drury et al. concluded, 'there is a need for high quality, multi-centric clinical trials to provide a robust evidence base for contemporary paediatric cardiac surgical practice' [2]. The authors bemoan, 'In this systematic review of the recent literature, we identified 333 RCTs in children's heart surgery from 34 countries reported since the turn of the millennium. These were mostly single-centre, Phase 2 trials that were not prospectively registered, recruited small number of patients without independent oversight and 


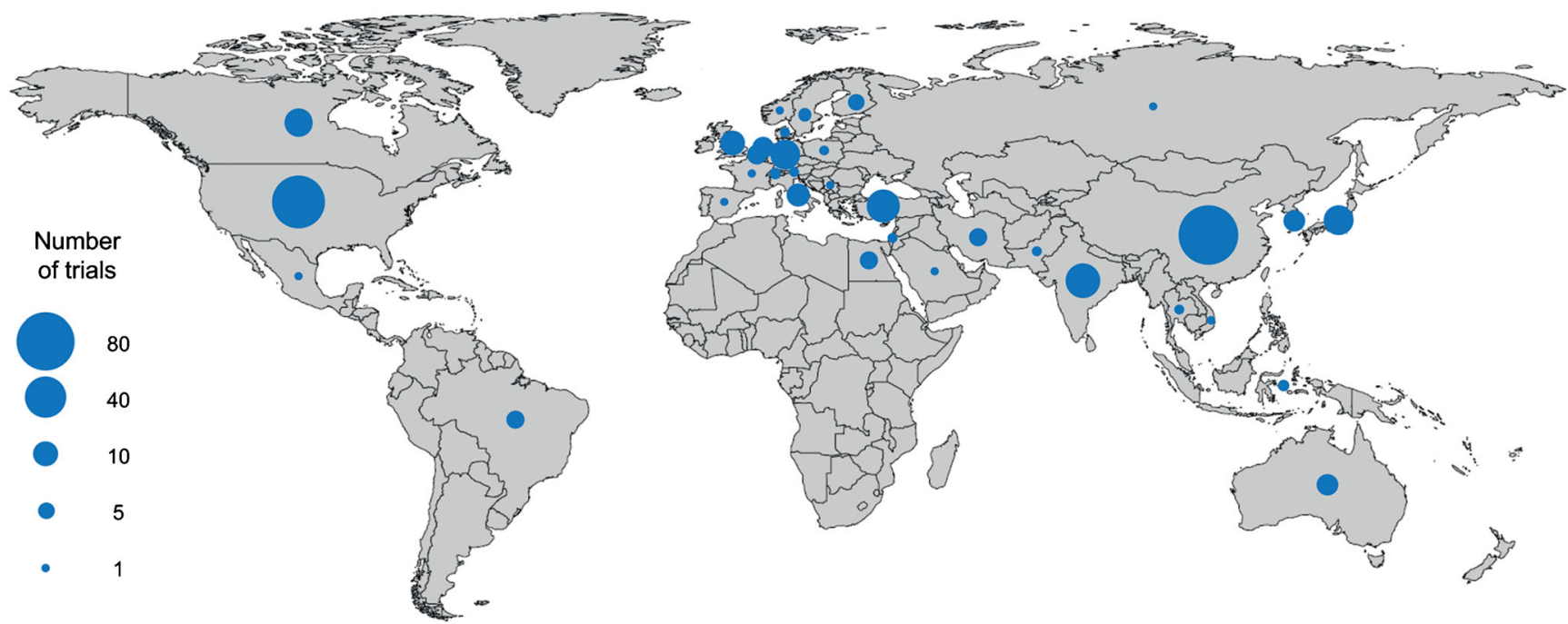

Fig. 1 World map of published trials by country of origin [2]

were not reported to international standards' (Figs. 1 and 2) [2]. Though phase 2 trials are important for safety and efficacy, it is the phase 3 clinical effectiveness trials which are practice informing. However, these are the ones which are glaringly few and far between (4.5\%) [2]. If this was not enough, even out of the studies that were conducted, only $29 \%$ were published in peer-reviewed journals [3], 'revealing a substantial publication bias and implying that these may be just the tip of a low-value, low-quality trial ice berg' [2].
Gaudino et al. recently showed that equipoise between efficacy of various surgical techniques, rapid evolution and changes in techniques, lack of funding and even very limited education, and thereby ignorance, in the field of clinical epidemiology amongst the surgeons are specific challenges faced for conducting trials in cardiac surgery [4]. All these factors are all the more applicable to congenital heart surgery. In fact, the steep learning curve and a wide gap in the surgical expertise, small number of cases and a myriad minor iterations of

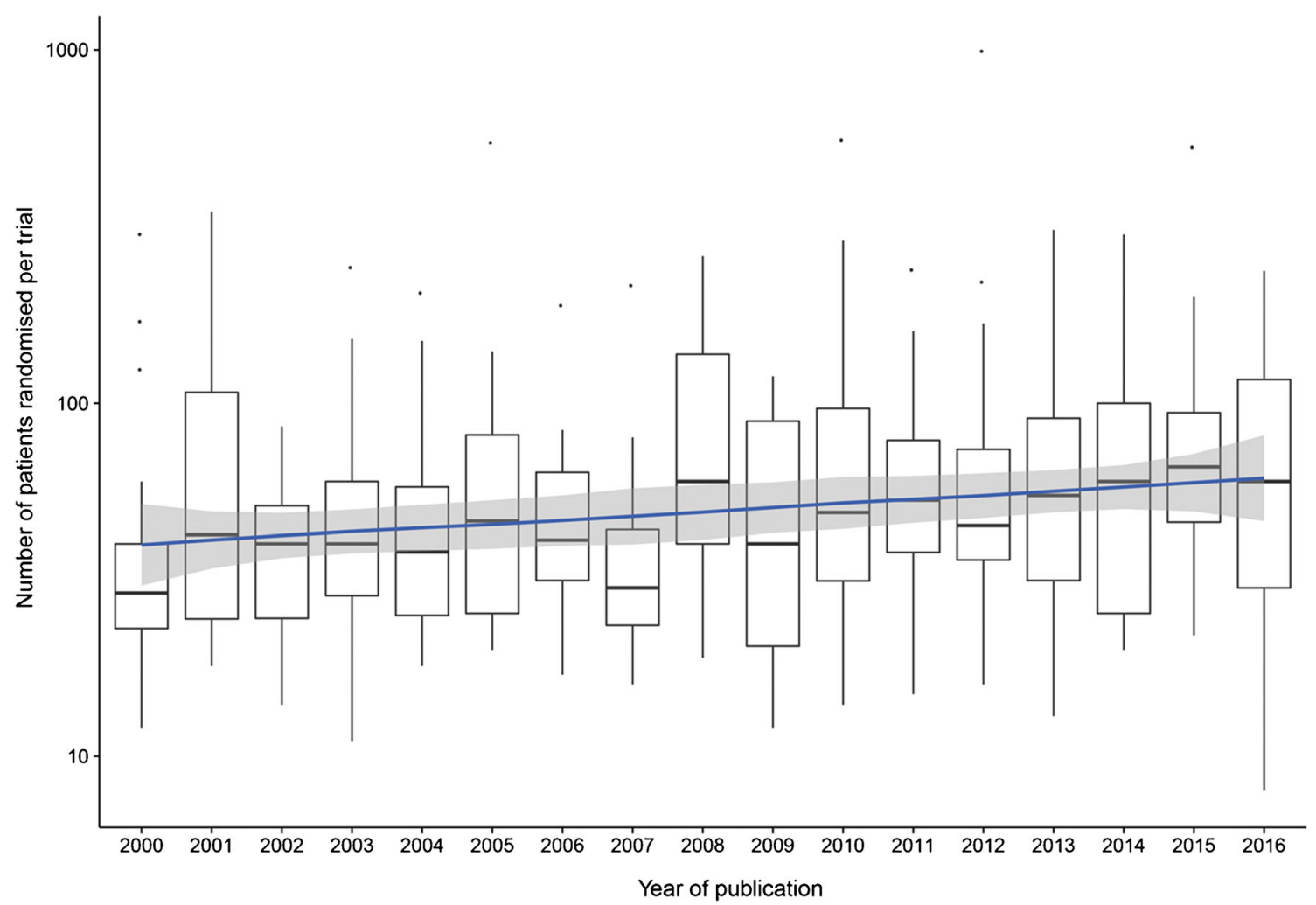

Fig. 2 Logarithmic Tukey box plot of the number of children randomized per trial by year. Linear regression line $\left(R^{2} 0.026, P=0.003\right)$ suggests no meaningful change over time [2] 
the same pathology can vitiate the trial design and analysis of results, making matters all the more arduous for conducting trials in paediatric cardiac ailments.

Though RCTs 'are the only approach to minimise bias and hidden confounders' [4], they may be logistically a difficult proposition. Therefore, at least a nationwide mandatory database and registry should be established. Registry data is also very relevant as it depicts actual real-world practices and may reflect patient heterogeneity, at times even better than RCTs. Unfortunately, we in India lack authentic registry data also, and thus, there is a double whammy handicap of lack of both formal and informal data. Indian Association of Cardiovascular and Thoracic Surgeons (IACTS), or the subspeciality dedicated Paediatric Cardiac Society of India, may like to take the lead towards addressing this long-felt need of the speciality. The funding for registry may not be as colossus, and therefore unlikely to be a deterrent, and can easily be borne by the respective professional associations. However, the 'will' and 'inclination' to take the bull by the horn needs to be re-discovered, or inculcated de novo.

Though it calls for collective action and participation, the onerous responsibility must lie with the well-endowed amongst us, who must rise to the occasion to provide scientific leadership and conduct rigorously designed, if possible multicentric, studies to inform clinical practice in a more definitive and robust manner. Hope this issue serves its purpose of stimulating and initiating a thought process, at least in some of us, on these lines, besides being a ready reckoner for your desktops.

Happy browsing.

\section{Compliance with ethical standards}

Conflict of interest The author declares that there is no conflict of interest.

Informed consent Not required.

\section{References}

1. Yadava OP. Heart transplant and mechanical circulatory support the last frontier? Indian J Thorac Cardiovasc Surg. 2020;36:S157S158.

2. Drury NE, Patel AJ, Oswald NK, Chong CR, Stickley J, Barron DJ, Jones TJ. Randomised controlled trials in children's heart surgery in the $21^{\text {st }}$ century: a systematic review. Eur J Cardiothorac Surg. 2018;53:724-31.

3. Shamliyan T, Kane RL. Clinical research involving children: registration, completeness and publication. Paediatrics. 2012;129:e1291e1300.

4. Gaudino M, Kappetein AP, Franco AD, et al. Randomised trials in cardiac surgery: JACC Review Topic of the Week. J Am Coll Cardiol. 2020;75:1593-1604.

Publisher's note Springer Nature remains neutral with regard to jurisdictional claims in published maps and institutional affiliations. 